\title{
Applying an Interspersed Online and Offline Teaching Strategy in Medicinal Chemistry to Cultivate Research Interest and Innovation Skills in Undergraduate Pharmacy Students
}

Huazhou Ying

Zhejiang University College of Pharmaceutical Sciences

Tao Liu

Zhejiang University College of Pharmaceutical Sciences

Rong Sheng

Zhejiang University College of Pharmaceutical Sciences

Wenteng Chen

Zhejiang University College of Pharmaceutical Sciences

Xiaowu Dong ( $\nabla$ dongxw@zju.edu.cn )

Zhejiang University https://orcid.org/0000-0002-2178-4372

\section{Research article}

Keywords: Medicinal chemistry, Cloud, Teaching System, Cultivation, Undergraduate.

Posted Date: September 28th, 2020

DOI: https://doi.org/10.21203/rs.3.rs-72179/v1

License: (c) (1) This work is licensed under a Creative Commons Attribution 4.0 International License.

Read Full License 


\section{Abstract}

Background: Medicinal chemistry is one of the most important professional courses for undergraduate pharmacy students. It plays an essential role in the cultivation of innovative pharmaceutical talents, especially for drug discovery and development.

Methods: We present here a new teaching system that integrates a cloud-based teaching platform, as well as applying an interspersed online and offline teaching strategy in an undergraduate medicinal chemistry course.

Results: The innovative teaching mode increases undergraduates' interest and understanding of medicinal chemistry topics as well as the frontiers and technologies in new drug discovery. Furthermore, it promotes effective communication between teachers and students resulting in increased research interest and innovation skills of undergraduates.

\section{Background}

The International Union of Pure and Applied Chemistry (IUPAC) defines medicinal chemistry as "a chemistry-based discipline, involving aspects of biological, medical and pharmaceutical sciences. It is concerned with the invention, discovery, design, identification and preparation of biological active compounds, the study of their metabolism, the interpretation of their mode of action at the molecular level and the construction of structure-activity relationships (SAR), the relationships between chemical structure and pharmacological activity for a series of compounds"[1]. For course setting of the undergraduate pharmacy major in Chinese universities, medicinal chemistry is an important professional core course, which is considered as a bridge between the basic courses (organic chemistry, inorganic chemistry, etc.) and other professional courses (pharmacology, pharmacy, pharmaceutical analysis, etc.). In China, this course usually begins in the fourth or fifth semester. The objective of the course is that undergraduates can analyze and explain the clinical medication with theoretical knowledge. Furthermore, the undergraduates will obtain the ability to design, synthesize and optimize drug molecules. However, because of a large variety of drug structures and a requirement of a broad knowledge base, which is closely related to other disciplines, medicinal chemistry has often been a difficult subject to teach in a classroom or lecture-based context. How to enhance undergraduates' interest in this course, engage them in the course content actively, and train their thinking ability is a big challenge[2].

At present, the pharmaceutical industry has an increased demand for innovative pharmaceutical professionals. Being the source of innovative drug discovery, medicinal chemistry courses plays a key role in cultivation of innovative pharmaceutical talents. It is therefore of paramount importance that the teaching method is appropriate, and that the undergraduates engage sufficiently with the course in order to retain the main points and apply the points practically[3].

Hence, it is of great significance to establish novel medicinal chemistry course resources and a teaching system in line with the characteristics of the current era that comprehensively integrate the skills and 
innovation needed for pharmacy major to become successful professionals and experts in the pharmacy field. As technology becomes more affordable and powerful, the use of cloud resources is rapidly increasing[4]. Cloud-based platforms are open systems that provide a vast variety of information for teaching and learning and is attractive to both teachers and learners[5]. An Educause Review article noted, "Institutions of higher learning are moving their operations to the cloud at a rapid pace"[6]. The cloud provides powerful means to foster undergraduate learning and enhance the quality of assessment[7]. Although it is still in the early stage for college educators, teaching through the internet with immense resources, an interspersed online and offline teaching strategy, and other cloud related forms of education will gradually become popular educational models. The cloud may have many advantages for a campus as a whole, this leads to the question of whether or not pharmaceutical educators might find cloud technology to be beneficial in their classroom and effective in cultivating pharmaceutical talents.

Based on this background, we explored a new teaching system by integrating a cloud-based teaching platform and applying a strategy of interspersed online and offline teaching. Based on this we constructed a professional curriculum and developed innovation skills of undergraduates. The goals of this study are: (a) improve undergraduates' interest and abilities to learn medicinal chemistry course; (b) enhance undergraduates' problem-solving skills, critical thinking skills, motivation and confidence; (c) cultivate undergraduates' scientific research and innovative abilities in drug discovery; (d) promote the understanding and communication between teachers and undergraduates.

\section{Methods}

\section{Study design}

In order to integrate cloud technology and classroom teaching, we used smartphone/pad as learning tools and communication devices. Electronic resources (courseware, micro-video, databases, etc.) are moved into the cloud to construct the cloud-based teaching platform (Figure 1), which provides the basis of "online and offline" teaching. It allows every undergraduate to join the class simply by accepting an invitation, where they would have access to all of the electronic resources. As such, the teachers can precede the lesson with background information, the students are more likely to derive meaning from a reading assignment in the platform. Furthermore, we use the number of scientific research projects undertaken by undergraduates as an indicator of their innovative practice (i.e. publishing scientific research papers). And we also assessed the improvement level of undergraduates' academic performance by the use of cloud-based teaching platforms.

\section{Releasing the core knowledge of medicinal chemistry courses (including drug structure, structure-activity relationship and synthesis method, etc.)}

Sources were released as PowerPoint, pictures, micro-video, and other types of form. The diversity of electronic teaching materials is much more than that of traditional teaching books. What's more, it is convenient for undergraduates to get and learn the subject through mobile terminals anytime and 
anywhere, promoting the learning interest of our students in study basic and frontier knowledge. At the same time, teachers can keep abreast of undergraduates' learning progress. Undergraduates can also share their study achievements or discuss with teachers without any delay.

\section{Sharing the examples of drug research and development and the latest research progress of medicinal chemistry}

Aspirin, for example, is regarded as a medical legend. We can share the story regarding the discovery of aspirin, as well as new research progress regarding aspirin and other COX inhibitors with the undergraduates[8]. We also can share the research progress of hot spots of the new drug development, such as cancer immunotherapy[9]. So that undergraduates will get a more comprehensive understanding of drug discovery process, and hopefully increase their interest in drug research.

\section{Integrating cloud technology into flipped classroom, case teaching, classroom testing and other teaching procedures}

To discuss the central problems with in a flipped classroom[10] or case-based teaching[11] more thoroughly, teachers can push important literature (such as the story of penicillin discovery, the development process of cimetidine), which may be difficult for students to acquire, and share their learning experience through the cloud platform. This allows our undergraduates to come to class prepared for discussion and active learning. Teachers can also open an online discussion platform, allowing undergraduates to brainstorm anytime and anywhere, and creating communities where teachers and undergraduates will communicate with each other encouraging undergraduates to explore topics through self-directed learning[12]. These strategies reduce undergraduate dependence on lecture as the only way to get knowledge. Additionally, teachers can easily monitor all students because the software application directly tracks learning progress (Figure 2A). Furthermore, the software application provides an interesting function of "sign in". It can help teachers grasp attendance of each undergraduate dynamically and more quickly (Figure 2B). In addition, testing undergraduates by using the cloud platform at anytime and anywhere is more flexible and it could decrease test anxiety. Test scores are released immediately after the test, which encourages undergraduates to study more efficiently. The results of the classroom tests from the course showed that the average score was 41.4 (100 as full mark) in the first chapter test at beginning of the semester, while it increased to 71.6 in the last chapter test at the end of the semester (Figure $2 \mathrm{C}$ ). To be of convenient, the software can summarize the error rate of each question, all undergraduates' test results and completion time (Figure 2D), so the teachers can roughly judge the difficulty of the questions, the teaching effect, and undergraduates' status of grasping courses, which provides basis for teaching reform.

\section{Participants}

The online teaching model has been implemented in 2014-2018. The faculty is composed of experts in medicinal chemistry from the Department of Medicine of Zhejiang University to ensure the smooth progress of teaching. The students in this study are composed of 171 freshman and 233 sophomore 
students majoring in pharmacy at Zhejiang University, who actively cooperated with the implementation of online teaching interaction and the filling of questionnaires.

\section{Data collection}

The software application can directly monitor the learning progress. In the teacher server window, teacher can directly click to view the learning progress and attendance rate of each student. We designed a questionnaire to evaluate this new teaching mode. The questionnaire contained many questions, including the difficulty of the medicinal chemistry course; recognition of the importance of the medicinal chemistry course; does cloud teaching applications improve learning efficiency; course website and cloud-based teaching platform, which one is preferred; cloud teaching platform learning time (weekly); the most difficult contents in the experiments; is cloud micro-video conducive to experimental teaching [See supplementary file].

\section{Ethical considerations}

Ethical approval or registration was not necessary in accordance with the ICMJE guidelines as our participants were undergraduate students majoring in pharmacy who could voluntarily sign up for the study. Although consent was not required, all participants were informed of the purpose of this study (i.e. evaluation and improvement of teaching strategy, aimed at informing the revision of the School's graduate program) during the teaching phase and again at the start of the class and all agreed before starting the teaching.

To ensure students did not feel obliged to participate, all students were allowed to withdraw from the study at any time, without having to provide a reason. Participants were guaranteed that all data would be processed anonymously and confidentially, and that participation was voluntary.

\section{Results}

\section{The application of Cloud Teaching Platform in Cultivating Innovation Ability}

We set up scientific research projects oriented by "New drug design and new drug synthesis". Then we release the user guides and micro-video tutorials of scifinder, chembl, drugbank and other databases which have been the most frequently used databases of medicinal chemistry. We adopted both online and offline teaching methods to guide undergraduates how to use these databases and solve practical problems. As a result, a number of undergraduates are willing to apply their knowledge to design and perform scientific projects (e.g. drug design, new synthetic methodology) can get the fund supported from the university and Zhejiang Province Education Office, such as Student Research Training Program (SRTP), Zhejiang Province university Student Science and Technology Innovation Program and National University Student Science and Technology Innovation Project. After using of the cloud teaching platform for five years, we found that the number of scientific research projects undertaken by undergraduates remarkably increased in the area of medicinal chemistry, with $8,7,12,5,10$ items approved in our 
university in 2014, 2015, 2016, 2017 and 2018 respectively, involving 24, 21, 28, 14 and 21 undergraduates respectively. The number of participated undergraduates was increased by $300 \%, 250 \%$, $400 \%, 130 \%$ and $250 \%$ when comparing to that of 2013 (6 undergraduates). In addition, there were a total of nine scientific research papers published by undergraduates through these innovative practices.

\section{Evaluating the use of cloud-based teaching platform}

In order to evaluate this new teaching mode, we designed a questionnaire and surveyed enrolled students (Table 1). The results indicate that: a) about $95 \%$ of undergraduates recognize the importance of medicinal chemistry. This fully confirms that sharing the medicinal chemistry related knowledges to undergraduates could play a positive guiding role for them; b) undergraduates have a high recognition for the "cloud teaching platform". Compared with the traditional course website, $95 \%$ of undergraduates choose the cloud teaching platform for learning, and more than 50\% students spend more than 3 hours weekly learning time on the cloud platform. This indicates that the cloud-based teaching platform can become a new carrier for undergraduates; $c$ ) the number of undergraduates who are willing to choose the projects from medicinal chemistry as their research training program are significantly increased, indicating that a large proportion of undergraduates approve the guidance of medicinal chemistry courses on their professional knowledge and the cultivation of their interest.

\section{Discussion}

Success in pharmacy requires not only a mastery of important pharmaceutical concepts, but also the skills to apply this knowledge to important societal issues and the capability of independent innovation. In order to better connect medicinal chemistry learning and cultivation of innovative skills within undergraduates, we set up a "second classroom" on the cloud platform.

We found that after watching a micro-video of experiment operation released from the cloud-based teaching platform, the average time used in the experimental operation in classroom was reduced by more than $30 \%$. Thus, greatly increasing the efficiency of experimental teaching and providing teachers more time to explain the experimental mechanism and practical application of the content, which are the most difficult parts of the experimental class for undergraduates (from the questionnaire, Table 1). In addition, through the micro-video about computer-aided drug design, microwave-assisted drug synthesis and other advanced courses of medicinal chemistry, undergraduates will understand the relevant knowledge of new drug innovation and master more innovative knowledge through active learning.

\section{Conclusions}

At present, all undergraduates are born in the Internet era. They have been influenced by electronic products since childhood and have great interests in them. We have applied a "cloud-based teaching platform" in medicinal chemistry. The online and offline interspersed strategy may offer students a new experience of "play in learning and learn in playing". The cloud-based teaching platform enhances 
undergraduate motivation and learning outcomes significantly. It promotes the interaction between the teachers and undergraduates. Eventually, it has positive effects on cultivating innovation ability. However, this innovative teaching mode requires teachers to invest more energy and puts forward higher requirements for teachers' teaching and scientific research quality. Next, we will focus on how to promote and benefit more colleges and universities.

\section{Abbreviations}

IUPAC: The International Union of Pure and Applied Chemistry; SAR: structure-activity relationships; SRTP: Student Research Training Program.

\section{Declarations}

\section{Ethics approval and consent to participate}

No, ethical approval or registration was not necessary in accordance with the ICMJE guidelines as our participants were undergraduate students majoring in pharmacy who could voluntarily sign up for the study. Verbal consent was obtained by the students before the study

\section{Consent for publication}

Not applicable.

\section{Availability of data and materials}

The datasets used and/or analysed during the current study are available from the corresponding author on reasonable request.

\section{Competing interests}

There are no conflicts to declare

\section{Funding}

Not applicable.

\section{Authors' contributions}

XWD designed this study. HZY and TL collected and analyzed the data. RS and WTC aided in analyzing and interpreting the results. HZY wrote the first draft of the manuscript. XWD revised the draft for important intellectual content. All authors read and approved the final manuscript, thereby taking full responsibility for the work and manuscript content.

\section{Acknowledgements}


Thanks for the software authorized by Beijing Mosoink Information Technology Co. Ltd.

\section{References}

1. Foye WO, Williams DA, Lemke TL: Foye's Principles of Medicinal Chemistry. 5th ed Lippincott Willams \& Wilkins: Philadelphia 2002.

2. Alsharif VFRaNZ: Staying alive. Advancing medicinal chemistry by enhancing student responsibility for learning. American Journal of Pharmaceutical Education 2002, 66:319-328.

3. Victoria F. Roche PJD, Marvin C. Pankaskie, Bruce L. Currie, Edward B. Roche, Robert D. Sindelar, James E. Wynn and S. William Zito: The status of chemistry content in the professional pharmacy curriculum_ Results of a national survey. American Journal of Pharmaceutical Education 2000, 64:239-251.

4. Pence HE: Moving Chemical Education into the Cloud(s). Journal of Chemical Education 2016, 93(12):1969-1971.

5. Fatima Ramzan Ali FH, Syed Muhammad Farid Hasan, Fouzia Israr, Yusra Shafiq and Hafiz Muhammad Arshad: Perception and attitude of pharmacy students towards learning tools. Pakistan Journal of Pharmaceutical Sciences 2015, 28(6):2185-2189.

6. Hall S: (Higher) Learning to Confidently Embrace the Cloud. https://er.educause.edu/articles/2015/4/higher-learning-toconfidently-embrace-the-cloud (accessed Aug. 22, 2016).

7. Brandriet A, Holme T: Development of the Exams Data Analysis Spreadsheet as a Tool To Help Instructors Conduct Customizable Analyses of Student ACS Exam Data. Journal of Chemical Education 2015, 92(12):2054-2061.

8. Gaziano JM, Brotons C, Coppolecchia R, Cricelli C, Darius H, Gorelick PB, Howard G, Pearson TA, Rothwell PM, Ruilope LM et al: Use of aspirin to reduce risk of initial vascular events in patients at moderate risk of cardiovascular disease (ARRIVE): a randomised, double-blind, placebo-controlled trial. The Lancet 2018, 392(10152):1036-1046.

9. Nam J, Son S, Park KS, Zou W, Shea LD, Moon JJ: Cancer nanomedicine for combination cancer immunotherapy. Nature Reviews Materials 2019, 4(6):398-414.

10. Wesley.Baker J: The "classroom flip":Using web course management tools to become the guide by the side, Selected Papers from the 11th International Conference on College Teaching and Learning. CCCU Annual Technology Conference:9-17.

11. Currie BCR, V.F.; and Zito, S.W.: Medicinal Chemistry Case Study Workbook. Williams and Wilkins: Baltimore MD, USA 1996.

12. Muir-Herzig RG: Technology and its impact in the classroom. Computers \& Education 2004, 42(2):111-131.

\section{Tables}


Table 1

Investigation form undergraduates of pharmacy on the use of cloud teaching platform.

\begin{tabular}{|c|c|c|}
\hline Question & Option & Proportion \\
\hline \multirow[t]{5}{*}{ The difficulty of the medicinal chemistry course } & Very easy & $0 \%$ \\
\hline & Easy & $5 \%$ \\
\hline & Moderate & $14 \%$ \\
\hline & Hard & $71 \%$ \\
\hline & Extrme & $10 \%$ \\
\hline \multirow{2}{*}{$\begin{array}{l}\text { Recognition of the importance of the medicinal chemistry } \\
\text { course }\end{array}$} & Recognized & $95 \%$ \\
\hline & Denied & $5 \%$ \\
\hline \multirow{2}{*}{$\begin{array}{l}\text { Does cloud teaching applications improve learning } \\
\text { efficiency }\end{array}$} & Yes & $67 \%$ \\
\hline & No & $33 \%$ \\
\hline \multirow{2}{*}{$\begin{array}{l}\text { Course website and cloud-based teaching platform, which } \\
\text { one is preferred }\end{array}$} & Course website & $5 \%$ \\
\hline & $\begin{array}{l}\text { Cloud-based teaching } \\
\text { platform }\end{array}$ & $95 \%$ \\
\hline \multirow[t]{4}{*}{ Cloud teaching platform learning time (weekly) } & Not Learning & $0 \%$ \\
\hline & Less than 3 hours & $48 \%$ \\
\hline & $3 \sim 5$ hours & $24 \%$ \\
\hline & Above 5 hours & $29 \%$ \\
\hline \multirow{6}{*}{$\begin{array}{l}\text { The most difficult contents in the experiments } \\
\text { (MultipleOptions) }\end{array}$} & Reaction mechanism & $68 \%$ \\
\hline & Experimental principle & $36 \%$ \\
\hline & Experimental operation & $0 \%$ \\
\hline & Instrument use & $5 \%$ \\
\hline & Structural analysis & $50 \%$ \\
\hline & Others & $9 \%$ \\
\hline \multirow[t]{2}{*}{ Is cloud micro-video conducive to experimental teaching } & Yes & $86 \%$ \\
\hline & No & $14 \%$ \\
\hline
\end{tabular}

\section{Figures}




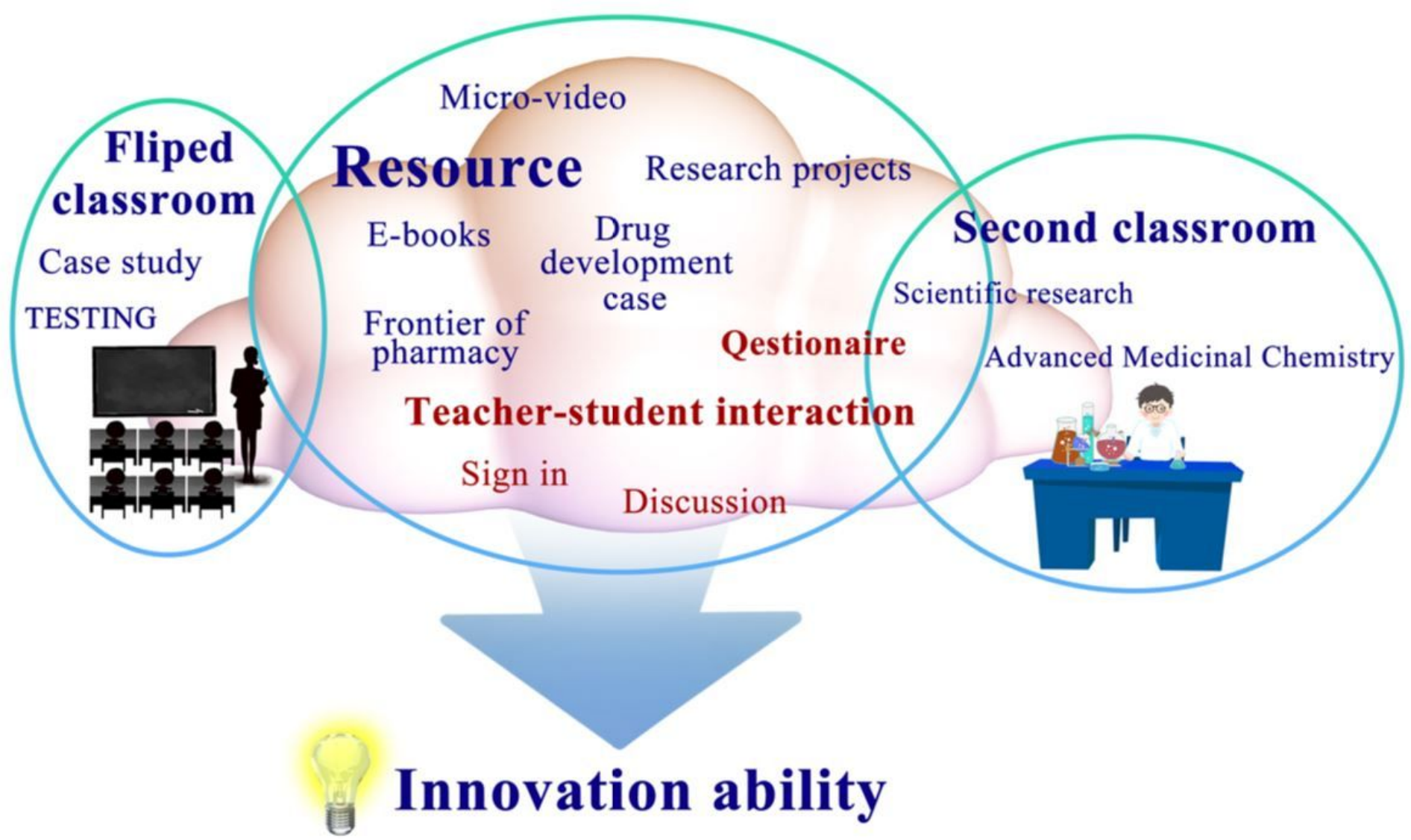

Figure 1

The Construction of "Cloud-based Teaching Platform". The picture was drawn by author HZY. 


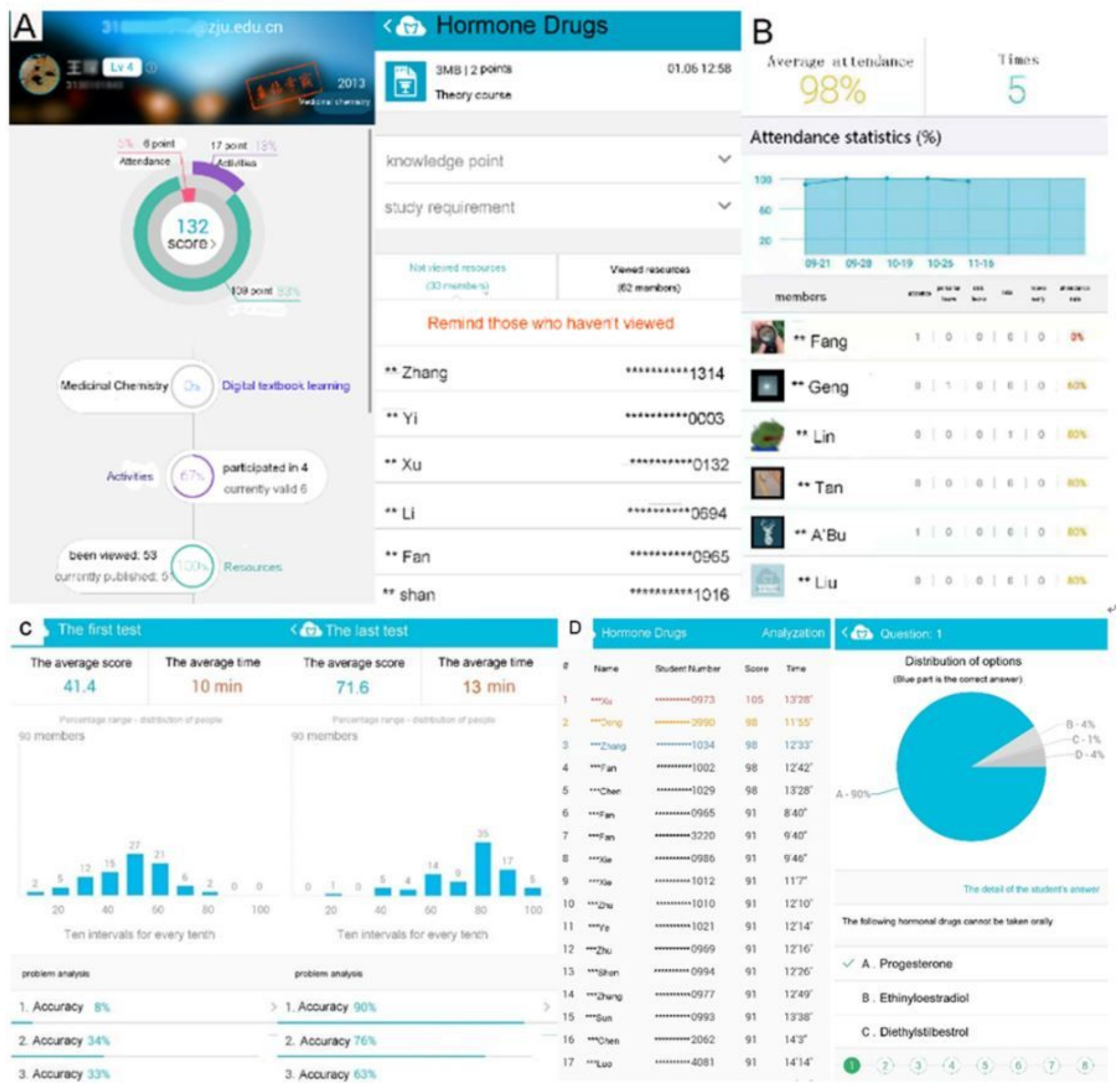

\section{Figure 2}

The function of cloud teaching platform. (A) The learning track; (B) The sign in statistics; (C) The average score of tests; (D) The test analyzation. The picture comes from screenshots of the software interface, which authorized by Beijing Mosoink Information Technology Co. Ltd.

\section{Supplementary Files}

This is a list of supplementary files associated with this preprint. Click to download. 
- Questionnaire.docx

Page 12/12 